\title{
LA CORPOREIDAD DEL MUERTO: EXHUMACIÓN E IDENTIDAD EN EL CASO DE LA GUERRA DE MALVINAS
}

\author{
The Corporeality of the Deceased: Exhumation and Identity \\ in the Case of the Malvinas War
}

\section{LAURA PANIZO*}

Fecha de recepción: 13 de julio de 2018 - Fecha de aprobación: 10 de noviembre de 2018

\section{Resumen}

En este artículo entenderé las disputas sobre los cuerpos de los caídos argentinos en la Guerra de Malvinas a partir de una perspectiva que vincule estudios del campo de la antropología de la muerte y del cuerpo. Primero, haré referencia a la forma en que un grupo de familiares se ha enfrentado a la muerte a partir de la ausencia del cuerpo. Luego, contextualizaré las disputas que se han dado entre ex combatientes y los familiares que hasta el 2017 se han negado a las exhumaciones de los caídos que yacían sin identificación en el cementerio de Darwin. Propondré focalizar en la "corporeidad" de los muertos ya que en tanto cuerpos/sujetos encarnan y reproducen relaciones sociales. Por último, haré una reflexión sobre el impacto de las exhumaciones en los familiares que, a pesar de su negativa inicial, han solicitado finalmente la localización de los cuerpos. De esta manera, se entenderá a la muerte como un proceso que se atraviesa a partir del tipo de presencia que el muerto tiene en la vida cotidiana de los vivos y de acuerdo a la ubicación y estado de los cuerpos, ya que estos están en constante movimiento como materialidad no acabada.

Palabras clave: Caídos en la Guerra de Malvinas; corporeidad del muerto; exhumaciones e identidad.

\section{Abstract}

In this article I propose to understand the disputes regarding the practices on the bodies of the fallen Argentines in the Malvinas War from a perspective that links studies from the field of the anthropology of death, and of the body. First, I will refer to the way in which a group of relatives has faced death from the absence of the body. Then, I will contextualize the disputes that have taken place between ex-combatants and the relatives who until 2017 have refused to exhumations of the fallen who were lying without identification in the cemetery of Darwin. I will propose to understand the bodies of the fallen attending to their "corporeality", since as bodies / subjects they embody and reproduce social relations. Finally, I will reflect on the impact of exhumations on family members who, despite their initial refusal, have finally requested identification for the location of the bodies. Then, what the experiences of the relatives and the resumed literature reveal to us, is that the dead body, like the living body, is in constant movement as unfinished materiality.

Keywords: Fallen in the Malvinas War; The corporeality of the deceased; exhumations and identity.

* Dra. en Antropología Social. Docente Universidad Nacional de San Martín, San Martín, Argentina. Investigadora Consejo Nacional de Investigaciones Científicas y Técnicas (CONICET), Buenos Aires, Argentina. El artículo se enmarca en proyecto de investigación de CONICET. Correo-e: laura.panizo@unsam.ar, laura.m.panizo@gmail.com 


\section{Introducción}

En este trabajo reflexiono sobre la temática de la ubicación e identidad de los cuerpos de los caídos en la Guerra de Malvinas ${ }^{1}$, que se viene discutiendo entre familiares de caídos y ex combatientes apenas terminada la guerra pero que en el último tiempo dio lugar a múltiples enfrentamientos a partir del lanzamiento del "Plan del Proyecto Humanitario sobre la identificación de los restos de soldados Argentino no identificados sepultados en el Cementerio de Darwin, Islas Malvinas" (de aquí en adelante $\mathrm{PPH}$ ). Dicho proyecto fue llevado adelante por La República Argentina, el Reino Unido de Gran Bretaña y el Comité Internacional de la Cruz Roja (CICR) entre el 2016 y 2017. Las tareas de exhumación de los cuerpos que yacen en tumbas no identificadas, se realizó entre junio y agosto del 2017 en donde participaron antropólogos del Equipo Argentino de Antropología Forense (EAAF) y expertos del Reino Unido y España. Quienes comenzaron con el pedido de identificación fueron principalmente familiares y ex combatientes que conforman la Asociación Combatientes de Malvinas por los Derechos Humanos (ACOMADEH), como los ex combatientes del Centro de Ex Combatientes Islas Malvinas de La Plata (CECIM) y ex combatientes y familiares de un Centro de Ex combatientes de Chaco (CESCEM-CHACO). Estos últimos, legitimaron su reclamo en el año 2011 a partir de un pedido judicial de recurso de amparo aludiendo al Derecho por la Verdad e Identidad. A partir de allí iniciaron las tratativas para pensar el $\mathrm{PPH}$, que fue acordado en el 2016. En marzo del 2017, integrantes de la Comisión Provincial por la Memoria (CPM) viajaron a las Islas Malvinas y visitaron el cementerio llevando carteles que, en apoyo a la ACMDH, reclamaban la identifi- cación de los "NN". Esta visita fue reprochada por familiares de la comisión de Familiares de Malvinas e Islas del Atlántico sur (de aquí en más Comisión de Familiares) que durante muchos años se negaron a la exhumación e identificación de sus seres queridos. Así, bajo el lema "Nuestros héroes no son NN" los familiares lanzaron una campaña en repudio a dicha denominación.

Este trabajo tiene el objetivo de proponer una vía de análisis sobre los sentidos dados a los cuerpos muertos, sus prácticas y denominaciones que vincule algunos estudios que se hicieron desde el campo de la antropología de la muerte y la antropología del cuerpo. Esta perspectiva nos posibilitaría entender a los cuerpos que, en palabras de Silvia Citro (2009) están atravesados por significados culturales, no solo como objetos de poder y luchas políticas sino que también encarnan relaciones sagradas entre vivos y muertos. En este sentido, los aportes desde la corporeidad, nos permitirían focalizar sobre un cuerpo muerto que, en tanto cuerpo/sujeto, tiene un "carácter activo y transformador en la praxis social" (Citro, 2009, p.49). Para ello trabajé con entrevistas realizadas a ex combatientes y familiares y con el registro etnográfico de más de 10 años de investigación. En este sentido, es importante mencionar que el artículo refiere a experiencias de familiares y ex combatientes registradas hasta diciembre del 2017, fecha en la que finalicé con el trabajo de campo. Pero antes de adentrarnos con la temática de las exhumaciones quisiera hacer una breve referencia a la forma en que los familiares se enfrentaron a la muerte de sus seres queridos a lo largo de los años a partir de la ausencia del cuerpo. 
Como primer punto es importante destacar que el gobierno dictatorial que gobernó La Argentina entre los años 1976 y 1983 y decidió recuperar a las Islas Malvinas a la fuerza en 1982 mandando tropas argentinas al territorio ocupado por los ingleses, fue responsable durante su gobierno de la detención clandestina, tortura, muerte y desaparición de miles de ciudadanos, entre otros crímenes. Luego de la rendición frente a los ingleses y terminado el conflicto armado que dejó un costo de 649 muertos argentinos, el gobierno aunque no reconoció la muerte de los desaparecidos de La Argentina continental sí lo hizo con las muertes heroicas de los soldados a través de normativas y comunicados oficiales (Panizo, 2011, 2015) ${ }^{2}$. Los familiares de los caídos no fueron informados clara y adecuadamente sobre el motivo de las muertes y el destino de los cuerpos, que fueron inhumados en su mayoría (y muchos sin identificar) en el cementerio de Darwin, Isla Soledad. La información sobre las muertes durante muchos años fue recolectada a partir de búsquedas personales en donde los testimonios de los ex combatientes sobrevivientes jugaron un rol fundamental. Por otro lado, los cuerpos en el cementerio que estaban sin identificar, representaban al héroe nacional que, sin importar nombre, grado profesional o políticas partidarias había dado su vida por la patria. En este sentido, algunos familiares elegían tumbas NN para tener una mediación simbólica con los muertos cuando visitaban el cementerio, función que cumplía también el cenotafio emplazado junto a las tumbas en el que están inscriptos los nombres de todos los caídos ${ }^{3}$.

Entonces, a diferencia de las formas habituales con las que se enfrentaban a las muertes "comunes", en donde la presencia de los muertos en el mundo de los vivos culmi- naba luego de periodos cortos de despedida y separación a través de prácticas realizadas con/ sobre el cuerpo muerto (como en el velatorio, el entierro o cremación), en el caso de los caídos en Malvinas, la muerte con ausencia del cuerpo ha sido y es enfrentada a través de prácticas novedosas. Estas funcionan en espacios públicos y domésticos en donde se veneran a los caídos de la guerra como héroes nacionales.

Entre estas prácticas se encuentran las misas del 2 de abril, "Día de las Islas Malvinas, Georgias del Sur y Sandwich del Sur"4. Los familiares eligieron esta fecha para realizar anualmente una misa en honor a los caídos en la guerra, en la Catedral Metropolitana, lugar que, por otra parte, hospeda desde 1882 los restos del General San Martín, el "Padre de la Patria" argentina. Una vez terminada la misa, los familiares haciendo una marcha mortuoria, llevan al altar ofrendas florales (649 pimpollos de rosas rojas que representan a cada caído). En dichas ceremonias, en donde los obispos que las presiden resaltan el deber que tiene la sociedad de honrar a los caídos por la patria y reivindicar a los combatientes que volvieron, concurren tanto familiares como ex combatientes, militares, amigos de los familiares, y un público general.

Otras prácticas relativas a la muerte en la guerra son los altares domésticos, espacios sagrados, dispuestos en las casas de los familiares que funcionan alrededor de la foto del muerto. A esta se le acercan objetos simbólicos como la imagen de la Virgen de Luján, rosarios, cruces, diplomas, objetos de conmemoración, u objetos que los familiares trajeron de los distintos viajes a Las Islas, como arena, caracoles, tosca del lugar, etc. En estos espacios domésticos se veneran a los muertos "como a los santos", se reza y se hacen peticiones (Panizo, 2015): 
Malvinas tiene como un pedacito, un rincón, que nosotros le llamamos "Altar a Malvinas y a tu ser querido (María Fernanda, 26-06-07).

Hay que tenerlos en un altar y pedirles cosas. Yo considero que son santos... yo soy muy religiosa y para mí el que da la vida por otro se convierte como que se inmolan sin pedir nada a cambio... entonces es como que vos sabés que de alguna manera... así como veneramos un santo... y pedirles cosas... por eso lo del altar... y yo te aseguro que nos ayudan (Nilda, 28-10-09).

Para entender las prácticas de los altares domésticos hay que tener en cuenta que para los familiares los cuerpos muertos sufrieron una transformación ontológica a través de la guerra, que junto con la idea de sacrificio los convirtió en seres sagrados ${ }^{5}$. Como ya he desarrollado en otros trabajos (Panizo 2011, 2015) para que el sacrifico no sea inútil, ya que la guerra se perdió, fue fundamental que el intercambio contractual que supone la idea de sacrificio sea obtener cierta soberanía simbólica de las Islas a través de los cuerpos que yacen en el cementerio. Es por eso que a partir de la guerra las Islas comenzaron a ocupar un lugar primordial en la cartografía simbólica de los familiares. La transformación de estas en una geografía sagrada se observa en el lenguaje metafórico de los familiares que, dentro del marco simbólico nacionalista, ubica a la Virgen de Luján (símbolo por excelencia de identidad de La Comisión), al cuerpo de los héroes, y a la tierra por la que pelearon dentro del mismo campo semántico. Así, mediante la idea de sacrificio y la metáfora orgánica que asocia al cuerpo y la "sangre derramada" con la tierra, los muertos se entienden como metonimia de la tierra:

\footnotetext{
Y vos tenés que saber que antes para mí las Malvinas no eran nada, un lugarcito en un mapa ahí perdido. Hoy ya no. Ya fue regado por el cuerpo de 649 caídos que regaron con su sangre ese suelo que es nuestro. Mi hijo está en esas tierras (Diana, 03/09/09).
}

Esta operación simbólica hace que los familiares entiendan a los muertos como si fuesen recursos nacionales para producir soberanía. De ahí el proceso de nacionalización de las muertes que permite la transformación del hombre en héroe, de héroe en santo y de santo en protector de la patria, como he referido en varias oportunidades (Panizo, 2011, 2015) y como se observará más adelante en el análisis del rol que ocupan los cuerpos en el cementerio. Entonces, la muerte, la falta del cuerpo, y la idea de sacrificio, confirieron al muerto la gracia de la santidad y los familiares logran establecer un tipo de relación recíproca con sus muertos, a quienes mantienen como agentes activos en su vida cotidiana.

Resumiendo, el entendimiento que los familiares que forman parte de la Comisión hicieron sobre la muerte en la guerra fue a partir de la ausencia del cuerpo y su lejanía espacial y a partir de la idea de sacrificio por la patria que incluye a los muertos en un colectivo de héroes que, sin importar nombres, procedencia, grado o destino en el campo de batalla, dieron su vida por un bien común a todos los argentinos (Panizo, 2011, 2015). En esta representación del héroe, la ubicación espacial del cuerpo y su forma de habitar la tierra (bajo el anonimato en muchos casos) tuvo un rol activo en la vida cotidiana de los vivos que llevaron a diferentes prácticas de comunicación con sus muertos. Es en este marco de entendimiento de la muerte en la guerra que se dan las disputas por las exhumaciones e identificaciones como veremos a continuación. 


\section{El cementerio de Guerra y la manipulación de los cuerpos}

Como durante los primeros seis meses de la posguerra el gobierno argentino no se ocupó de, según el pedido británico "repatriar" a los caídos, los ingleses concentraron a los cuerpos de los soldados argentinos en el cementerio ubicado en Darwin, Isla Soledad. Los soldados que no pudieron ser identificados fueron enterrados en tumbas con la inscripción "Soldado Argentino Sólo Conocido por Dios". Hoy en día en el cementerio hay 237 cuerpos sepultados, de los cuales 123, hasta principios de diciembre del 2017 no estaban identificados. Estos cuerpos están sepultados en 230 tumbas individuales y dos fosas comunes: una que lleva el nombre de 4 tripulantes de un helicóptero y otra de 5 tripulantes de un Lear Jet derribado (en donde se supone que hay solo dos o tres cuerpos). La tumba del Lear Yet aunque no contenga todos los cuerpos fue designada administrativamente por representantes de la Cancillería Argentina y de la comisión de Familiares con el nombre de los 5 caídos. La decisión de denominar la tumba colectiva de esta manera, fue sostenida por un representante de la Cancillería Argentina, desde una perspectiva "humanitaria":

Como no se puede ir a isla Borbón, porque no se llega fácilmente... para posibilitar que todos los familiares de caídos del Lear puedan hacer su duelo y puedan estar en el cementerio, se consideró que los 5 del Lear estén enterrados en el cementerio de Darwin, sabiendo que, 2 ó 3, no están. Son sepultados, llamémosle, administrativamente (Guillermo, 3/06/ 20096).

Dentro de la administración que la Comisión de Familiares hizo del cementerio junto con Cancillería Argentina, está la construcción del Monumento a los caídos y el reemplazo de las cruces construidas por los ingleses por unas cruces hechas de madera de lapacho, más resistentes. Entonces, el cementerio fue por muchos años cuidado y administrado por la Comisión de Familiares que han organizado viajes a las Islas para su visita desde el año 2000. A pesar de que muchos cuerpos no estaban identificados, la Comisión de Familiares se negó a las identificaciones desde los primeros años de la posguerra. Los argumentos de la negativa referidos en la arena pública y en las conversaciones privadas, estaban relacionados al hecho de que la exhumación e identificación podría traer como consecuencia el reclamo de los diferentes familiares de traer los cuerpos a La Argentina continental y no estaban de acuerdo con "desmantelar" el cementerio. Es decir, una postura política bien marcada respecto a la soberanía sobre las islas y sobre el rol que deberían jugar los muertos en las tierras perdidas:

El sentimiento que prevaleció en los familiares fue que la mejor manera de rendir homenaje a sus seres queridos, era enterrarlos en la tierra por la que habían peleado?.

Las islas son argentinas... y para mí está enterrado en la República Argentina... no tiene por qué movilizarse de ahí su cuerpo, ni ser exhumado..." (Nelly, 28/10/2007).

Hay algunos mal intencionados que con la cuestión del derecho humanitario lo único que están haciendo es sirviendo al imperio, porque hay un sector del Reino Unido que lo único que quieren ellos es sacar todo vestigio que haya quedado del conflicto y que nosotros no lo vamos a cumplir (Horacio, 25/05/206).

Así fue que no solo cada familiar negaba la identificación de su caído, sino que se oponían a las identificaciones en general. Entonces nació la idea de los familiares de realizar los viajes para visitar el cementerio, se impulsó el proyecto de construcción del Monumento a los caídos y se reemplazaron de las cruces construidas por 
los ingleses por unas más resistentes. De esta manera, la construcción del monumento que lleva todos los nombres de los caídos, no tuvo solo el objetivo de generar un lugar simbólico donde ofrendar a todos los muertos sino el de reafirmar su postura frente a la ubicación de los cuerpos. Así, refieren los familiares respecto al cementerio como "la única presencia permanente de los argentinos en nuestras islas durante la postguerra" o como "banderas argentinas" que reclaman por su territorio.

El Monumento, si bien fue llevado a las Islas en el año 2004, fue inaugurado en el año 2009 con la entronación de la Imagen de la Virgen de Luján, un evento financiado por el Estado argentino y gestionado, junto con la Comisión de Familiares, por Cancillería Argentina. Este mismo año se sancionó en el Congreso una ley que declaraba al cementerio como lugar Histórico. La comisión de familiares ha sentido como un logro la sanción de dicha ley, ya que se creían legitimados para la administración de los cuerpos:

La Comisión de Familiares de Caídos en Malvinas e Islas del Atlántico Sur tiene la inmensa alegría de informar que anteayer se aprobó en la H. Cámara de Senadores de la Nación, la ley que declara LUGAR HISTORICO AL CEMENTERIO DE GUERRA de los Caídos en Malvinas e Islas del Atlántico Sur, emplazado en Darwin (...) Como lo afirma la Ley, cualquier iniciativa que se pretenda desarrollar a futuro en el Cementerio de Darwin, deberá ser consultada con la Comisión de Familiares de Caídos en Malvinas, así como con la Comisión Nacional de Museos, Monumentos y Lugares Históricos. Esta medida trae enorme tranquilidad a todos aquellos cuyos seres queridos yacen sepultados en el Cementerio de Darwin, pues no han faltado a lo largo de los 27 años de postguerra, sectores o individuos que han intentado profanar el bien hoy protegido legalmente, con argumentos pseudo humanitarios como la propuesta de identificar los restos o la colocación de placas con nombres propios, etc ${ }^{8}$.
La referencia a individuos "que han intentado profanar el bien hoy protegido legalmente, con argumentos pseudo humanitarios como la propuesta de identificar los restos" da cuenta de la disputa que se venía dando acerca de los cuerpos. Pero si bien la ley implementaba que se convendría con la Comisión de Familiares las medidas pertinentes a efectos de asegurar la custodia de los muertos, cuando se inició el $\mathrm{PPH}$ fueron consultados los familiares de todo el territorio argentino individualmente y no la Comisión de Familiares, como institución. Por otro lado, aunque los primeros argumentos de la negativa a las exhumaciones por parte de la Comisión de Familiares estaban asociados a la negativa de traer los cuerpos a La Argentina continental, la iniciativa de exhumar para identificar los cuerpos no contemplaba el traslado de los cuerpos como parte de una política general, aunque podían tratarse pedidos individuales. De hecho, cuando en agosto del 2017 se terminó con la tarea de exhumar los cuerpos para su identificación, todos ellos fueron inhumados nuevamente en las tumbas en las que yacían.

Aunque la Comisión de Familiares se negaba a las exhumaciones, a medida que avanzaba la iniciativa del PPH los familiares grabaron videos que hicieron circular por las redes sociales en donde apoyaban la iniciativa de las identificaciones, pero solicitaban el compromiso de que los cuerpos quedasen en las islas. Así, con un testimonio fílmico en primera persona, los familiares involucraban a la sociedad a acompañarlos en este pedido:

Soy Delmira de Cao, mamá del Soldado maestro, Julio Rubén, Cao, integrante de la comisión de Familiares. Estamos de acuerdo todas las mamás en acompañar a las madres que quieren localizar los cuerpos en nuestras Islas en Darwin, pero sí con el compromiso de que la Cancillería Argentina y el Gobierno nos firmen 
un documento haciéndose cargo de que los cuerpos no van a ser trasladados al continente, van a quedar en Darwin. El 9 de Marzo nos movilizaremos junto a la Confederación de ex combatientes, nuestros veteranos de Guerra, Héroes de la Patria ${ }^{9}$.

Luego de esta campaña, muchos familiares accedieron a dejar su muestra de ADN para la identificación, aunque se habían negado anteriormente. Ahora, las declaraciones en contra del PPH no referían a las identificaciones en sí, sino a cómo había sido tratado el tema:

Hoy, 35 años después, María Fernanda preside la Comisión de Familiares de Caídos y hace un par de meses, junto a su madre, proporcionó una muestra de sangre para que la Cruz Roja pueda cotejar sus datos con los del cementerio Darwin y así localizar el cuerpo de su hermano. Sin embargo, tiene sus reparos con respecto a cómo se gestó la iniciativa de cruzar los datos. "Se hizo a los ponchazos"10 y no nos avisaron como correspondía ${ }^{11}$.

Los "reparos en cuanto a cómo se gestionó la iniciativa" se deben, como habíamos mencionado, a que nunca se les consultó como institución sobre la temática y también a que no participaron de la diagramación del proyecto. En este sentido, cuando se empezó a pensar el PPH desde el gobierno presidido en ese entonces por Cristina Fernández de Krichner, se nombró por decreto a Ernesto Alonso, del CECIM, como el presidente de la Comisión Nacional de Ex Combatientes y a Norma Gómez, hermana de un caído de Chaco, como representante de los familiares para dicha Comisión. Por lo tanto, que la Comisión de Familiares se haya quedado afuera de Comisión Nacional que oficiaba de interlocutora con el gobierno se vio agravado por el hecho de que los ex combatientes que terminaron teniendo una participación directa en la conformación del $\mathrm{PPH}$ pertenecen al
CECIM, un organismo con la cual Familiares de Malvinas se encuentra enfrentada históricamente por sus formas muy diferentes de dar sentido a la muerte y a la experiencia de guerra. Esto es así fundamentalmente porque por parte el CECIM y el CESCEM-CHACO junto con otras agrupaciones que conforman la ACOMADEH, reclaman las identificaciones de los caídos junto con otra serie de reclamos vinculados a las violaciones de los Derechos Humanos en donde se solicita el juicio y castigo a los militares que "violaron los Derechos Humanos" dentro de la guerra, a través de torturas en el campo de batalla, muerte por hambre o reducción a la servidumbre. En este sentido el reclamo se llevó a la arena pública bajo las consignas de memoria, verdad, justicia y soberanía, asimilando sus denuncias a la de los de los organismos de Derechos Humanos relativas a la desaparición de personas bajo la dictadura y entendiéndose como "víctimas" de la última dictadura militar. Por otro lado, los familiares de la Comisión focalizan en el héroe y la forma de dar sentido a la muerte no fue desde la victimización sino abstrayendo la guerra de la Dictadura Militar. Así, los familiares trabajan cotidianamente para que los héroes de Malvinas sean reconocidos por la sociedad como héroes que al igual que los próceres que los antecedieron sacrificaron su vida por la patria. Entonces, el CECIM, por ejemplo, fue un organismo que jugó un rol importante como opositor en la construcción de la identidad de la Comisión de Familiares y a la de otros ex combatientes en la arena pública: “¿vos estas con el CECIM? ¿Sos una víctima? Porque nosotros no somos víctimas, somos héroes de la guerra" (Daniel, 15-08-2016).

Si en un primer momento los familiares fundamentaban la negativa a las exhumaciones por 
temor a que se sacaran los cuerpos del cementerio, el porqué de este rechazo varió a lo largo de los años. En el último período antes de que se llevara adelante el PPH, los familiares de la Comisión focalizaron específicamente sobre la forma de denominación de los muertos. Las manifestaciones públicas en torno a este repudio se acentuaron, como ya he mencionado, cuando una comitiva de la Comisión Provincial por la Memoria viajó a las islas Malvinas apoyando el reclamo por la identificación de los NN:

Los Familiares de los soldados argentinos caídos en Malvinas e Islas del Atlántico Sur queremos expresar nuestro más profundo dolor ante la inexplicable actitud de los integrantes de la Comisión de la Memoria de la Provincia de Buenos Aires que, encabezados por Adolfo Pérez Esquivel, viajaron a las Islas Malvinas para mancillar la memoria de nuestros seres queridos... En primer lugar, queremos repudiar la actitud de sus integrantes, cuando se refirieron a nuestros hijos, esposos, padres, hermanos, como a "NN." Nuestros seres queridos han sido declarados como "Héroes Nacionales" mediante la Ley 24.950 del año 1998, nombrando a los 649 por orden alfabético. En el Cementerio de Darwin no hay "NN.", hay soldados reconocidos por el Estado Nacional y por el conjunto del pueblo argentino... No podemos entender la persistencia de una campaña de desmalvinización, que trata de convertir a nuestros seres queridos en "víctimas de la dictadura militar", cuando murieron peleando contra las fuerzas británicas ${ }^{12}$.

Resulta llamativo que para la Comisión de Familiares nunca fue eje central reclamar al Estado ni a la sociedad, sino homenajear y rendir honores a los caídos en tanto muertos nacionales y patrióticos. Aunque el enfrentamiento con algunos grupos de ex combatientes y familiares se retrotrae a los inicios de la posguerra, es recién cuando se activa la posibilidad de exhumar los cuerpos que los familiares empiezan a accionar en la arena pública a través de escarches y campañas de concientización. En este sentido, el devenir en activistas, se vio impulsado por la ejecución del $\mathrm{PPH}$, lo que visualiza, como desarrollaremos más adelante, la agencia del cuerpo muerto en el contexto social.

Para abordar la temática de las exhumaciones y entender el porqué de un sostenido rechazo a las identificaciones propongo focalizar el análisis en las relaciones generadas entre los vivos y los muertos. Veamos cómo los aportes de la antropología de la muerte y la corporeidad, nos ayudan a entender de qué manera estas relaciones y la forma en que el cuerpo muerto habita la vida social de los vivos, se retroalimentan recíprocamente.

\section{La corporeidad de los muertos: su agencia y lugar en el mundo.}

Aunque en la inquietud inicial por la temática de la muerte en antropología se encuentran trabajos que resaltan la importancia de la presencia del cuerpo en el contexto ritual, son pocas las investigaciones que ponen en el cuerpo muerto el foco de atención. Entre éstas, se destaca el trabajo de Robert Hertz (1990) quien a través de etnografías sobre Indonesia hace un estudio detallado de las prácticas funerarias prestando una especial atención al caso de las dobles exequias. Uno de los aportes más importantes realizados por Hertz es el haber hecho hincapié en la necesidad de enfatizar en el tratamiento y el estado del cuerpo y en proponer un paralelismo entre el estado del cuerpo y el destino del alma en el proceso ritual. Esta última tiene al igual que el cuerpo muerto una estancia temporal en la tierra y vive al margen entre dos mundos. Hasta que el cuerpo no haya sido depositado en su sepultura 
definitiva, el alma no se integra finalmente en el mundo místico de las almas y frecuenta los lugares que habitó en vida. Estas visitas pueden transformarse en peligrosas para los sobrevivientes en caso de que estos no cumplan con los rigurosos rituales de luto (1990).

Un libro de reciente publicación compilado por Elizabeth Ansett, Jean-Marc Dreyfus y Sévane Gariban (2013) retoma la propuesta de Hertz de focalizar sobre las prácticas ejercidas sobre los cadáveres, con el objeto de en encontrar en las funciones simbólicas y materiales asignadas a los cuerpos muertos. Los autores de dicha compilación, no se detienen tanto en las relaciones entre los deudos y los muertos resaltadas por Hertz, sino en la clave para la comprensión de procesos de producción de violencia de masa y genocidio. Por ejemplo, el antropólogo Nigel Eltringham (2013) que analiza el caso del genocidio en Ruanda, propone una mirada que focalice sobre la relación entre ocultamiento y exhibición, atendiendo a la calidad discursiva de la disposición de los cuerpos. El trabajo de la antropóloga Anne Yvonne Guillou (2013) focaliza sobre la integración sagrada entre cuerpo y tierra con el objetivo de comprender a la sociedad Camboya del post genocidio y pone énfasis en la forma en que los aldeanos se mueven alrededor de las fosas de acuerdo a las creencias acerca de las mismas y de los muertos, entablando una especial relación entre vivos y muertos. Así también, la antropóloga Elizabeth Anstett (2013), destaca una preocupación sobre las representaciones acerca de las fosas comunes y las exhumaciones en las fosas del Gulag de la Rusia post-Soviéticas y, como una extensión de los trabajos de Katherine Verdery, la autora se pregunta por la vida política y religiosa de los cuerpos muertos. Algunas de estas propuestas me sirven como disparadores para pensar el caso aquí planteado. Por ejemplo, la propuesta de Eltringham de entender al cuerpo como vehículo discursivo en la manipulación de los cuerpos del genocidio en Ruanda nos puede iluminar al momento de pensar la disposición de los cuerpos en el cementerio.

Sin embargo, como veremos a continuación, propongo una visión complementaria para entender al cuerpo muerto más allá de su función representacional. Así también, en el trabajo de Guillou que focaliza sobre la integración sagrada entre cuerpo y tierra que provoca una continua comunicación entre vivos y muertos, encontramos cierta similitud con nuestro caso, sobre todo a partir de la idea del cuerpo del caído en Malvinas que se fundió en la tierra y hace soberanía simbólica sobre las islas. Siguiendo esta misma perspectiva, nos alineamos con el trabajo de Anstett, que se pregunta por la vida política y religiosa de los cuerpos muertos. Ya que el cuerpo es significativo a través de la forma en que es interpretada la muerte específica de una persona, en el caso de la Guerra de Malvinas el cuerpo de los caídos, puede devenir en símbolo que expresa deseos de legitimación o reivindicación de un grupo dado (Verdery, 1999). Así, desde esta perspectiva, de acuerdo a los significados asignados al muerto y a la forma en que se los identifican como sujetos históricos (víctimas o héroes de la dictadura, por ejemplo) es que los familiares podrían entender las prácticas que debieran o no hacerse sobre los cuerpos, ya sean referidas a las identificaciones o a su ubicación espacial. Las disputas por los cuerpos pueden entenderse como disputas político/ideológicas y la negativa a las exhumaciones y a las denominaciones de los cuerpos como NN, remitiría a un entendimiento determinado sobre la muerte 
en la guerra en el marco de la historia reciente, y a un entendimiento del cuerpo como símbolo político que cumple una función soberana sobre la tierra.

Pero atendiendo a la forma en que los familiares se han enfrentado a la muerte a lo largo de los años, podríamos pensar que el cuerpo del caído en el cementerio implica no solo una soberanía sobre el territorio, ni una forma de expresar un tipo de identificación con la historia reciente, sino también una forma ontológica determinada de establecer relaciones con los vivos. En este sentido es sugerente retomar el trabajo de Francisco Ferrándiz (2011), que plantea la vida asociativa, mediática, jurídica, científica y emocional de los cadáveres exhumados de los fusilados en la Guerra Civil española. En la vida emocional de los cadáveres, dice el autor, es en donde se inscriben las formas de reparación y duelo familiar que tienen lugar bajo las tecnologías del conocimiento científico que permiten las identificaciones (2011). Aunque el autor no desarrolla este punto, quisiera usarlo de puente para plantear mi postura respecto a la forma de abordar la temática de los cuerpos muertos remarcando la agencia de estos. El artículo recientemente citado de Ansett, aunque focaliza sobre los "usos" del cuerpo muerto, da un guiño a mi perspectiva al llamar la atención sobre la forma en que el cuerpo muerto interpela a los investigadores en el trabajo de campo. De hecho, en un trabajo anterior he reflexionado sobre la forma en que la experiencia con la muerte "cuerpo a cuerpo" en el marco de las exhumaciones, ha cuestionado mis categorías nativas y ha hecho que me sienta corporalmente afectada y comprometida (Panizo, 2016a). Entonces, mi propuesta radica en sumar a los aportes recientemente citados las contribuciones de la antropología del cuerpo vivo/vivido como línea de investigación complementaria que nos permita, por un lado, entender retomando a Hertz, la forma en que el tratamiento y el estado del cuerpo repercute sobre las relaciones entre vivos y muertos, y por otro lado, focalizar en la agencia del cuerpo muerto por su forma de "estar en el mundo".

Para ello, quisiera comenzar con los aportes de Silvia Citro (2009) quien considera que la materialidad del cuerpo y su experiencia práctica están atravesadas por significados culturales. La autora, a partir del reconocimiento de esta constitución material-simbólica de la corporeidad, propone el concepto de cuerpos significantes, y la idea de que quienes participan en la performance ritual habitan una experiencia que contribuyen a constituir las identidades (2009). Esta perspectiva nos ayuda a explicar por qué en el caso de los caídos en Malvinas utilizo la palabra cuerpo muerto, y no cadáver, incluso, aunque se suelan llamar "restos", cuando se trata de material óseo que es exhumado y llevado a una posterior identificación. Como ya he referido en otras oportunidades, la elección se debe porque entiendo que lo que determina al muerto en tanto tal dentro de la organización social, no es simplemente su cuerpo o los "restos" encontrados de él, sino una conjunción de prácticas sociales que, junto con signos, certificados, y una simbología mortuoria específica, otorgan reconocimiento social a la muerte (Thomas, 1993). Entonces, siempre que estemos hablando de la identidad (individual o colectiva) de un muerto determinado, no hablo ni de restos ni de cadáver, sino de un cuerpo muerto, asociado a una persona específica, con toda la significación que conlleva. Es decir, hablo de cuerpo muerto, para hacer referencia al carácter socialmente construido del cadáver. 
A los aportes de Citro sobre los cuerpos significantes se pueden sumar también la perspectiva del embodiment. Este concepto que incluso es retomado por Citro, ha sido utilizado por muchos autores desde las ciencias sociales para focalizar sobre la experiencia corporal y la reflexividad. En primera instancia, Merlou-Ponty, propone entender al sujeto como un sujeto corporizado, que debe entenderse a la vez en su relación con el mundo (1975). Así sostiene el autor, que el cuerpo humano por ser un cuerpo "vivido" es en sí mismo un sujeto y que este sujeto es un sujeto corporizado. Michael Jackson (2010) retoma el concepto de "cuerpo vivido" de Merleau-Ponty, para discutir con los estudios del cuerpo que han tendido a interpretar la experiencia corporizada en términos simbólicos y semióticos. En este sentido, Thomas Csordas (1999), también retoma las propuestas fenomenológicas desarrolladas por Merleau-Ponty de conocer el mundo a través del cuerpo y propone una distinción metodológica entre cuerpo y embodiment, para hacer referencia a los múltiples modos de corporización y estilos de objetivación del cuerpo que son fundantes para la comprensión de la cultura. El cuerpo, una entidad biológica y material, estaría diferenciado del embodiment, al cual define como "un campo metodológicamente indeterminado, definido por la experiencia perceptiva y por un modo de presencia y agencia en el mundo" (1999, p. 145) ${ }^{13}$. Csordas, que sigue la línea de Jackson, propone la perspectiva del embodiment como un paradigma complementario al paradigma de la antropología del cuerpo que entiende al cuerpo como representación (Csordas, 2010). Así, dice el autor, el enfoque fenomenológico corporizado del cuerpo como ser-en-el-mundo, no debe negar el estudio de los signos con respecto al cuerpo, sino comple- mentarlos (2010). Estos aportes resultan significativos porque me interesa ver a la corporeidad no solo desde una perspectiva discursiva, sino sobre la forma en el estado del cuerpo repercute en la vida social de familiares.

La perspectiva del embodiment y la corporeidad nos ilumina porque nos permite destacar del cuerpo muerto su entidad biológica y material, su construcción simbólica, su significado representacional, y también su ser-enel-mundo, al generar experiencias transformadoras en el contexto social a propósito del muerto y los deudos. Entonces, no me interesa focalizar el cómo se posee o se hace uso del cuerpo sino lo que el cuerpo/sujeto con su historia y prácticas experimentadas, propone. Así, el potencial del cuerpo muerto radica en su capacidad de generar prácticas y relaciones a partir de su modo de "estar en el mundo". Claro que la gran diferencia entre el cuerpo/ sujeto del muerto y el del vivo, es que el muerto está librado al uso que otros puedan hacer de su cuerpo. Así describe Giorgio Agamben retomando a Aristóteles, (2014) al cuerpo del esclavo en tanto máquina que no se destina a la producción sino a su uso. El esclavo "pese a ser humano, por naturaleza es de otro y no de sí" (2014, p. 26). De esta manera, lo que no posee el esclavo (ni tampoco el muerto) es la energía o virtud, para hacer uso de su cuerpo. Esta condición de los muertos, dispuestos para que otros puedan manipular sus cuerpos, es lo que llamó a los investigadores a focalizar sobre las representaciones y sus usos simbólicos y políticos, tal como lo expresa Ansset, acerca de la compilación recientemente citada: "el análisis de los usos religiosos, identitarios, económicos o políticos que los propios cadáveres pudieron llegar a suscitar... no pudieron conseguir hasta 
ahora constituir un terreno de estudio en sí mismo" (2013, p. 11). Pero aquí, lo que me interesa proponer, como una forma de abordaje complementario al de los usos y sus representaciones, es la capacidad de agencia del cuerpo en el contexto social a partir de su constitución como cuerpo/sujeto. De esta manera, las prácticas sobre ellos se retroalimentan recíprocamente con su condición ontológica, lo que propone, en esta retroalimentación, determinadas relaciones sociales.

Entonces, para pensar en la agencia del cuerpo muerto en el contexto social, propuse hablar en un primer momento del embodiment del muerto. La potencialidad de esta metáfora, radica justamente, como sostiene Turner (2002), en yuxtaponer dos términos que forman parte en principio, de dos campos semánticos distintos (muerte-vida) para formar una misma idea en donde las características de ambos temas a los que los términos hacen referencia, sin desplazarse unas a otras, se fundan en una acción simbólica, superadora y polifónica (Turner, 2002). Así, como dice Turner, en la metáfora los dos pensamientos se activan juntos "engendrando" pensamiento en su coactividad (2002). Cuando presenté este trabajo en la mesa Corporalidades, procesos de subjetivación y nuevas metodologías etnográficas de la última Reunión de Antropología Social, (RAM, 2017, Misiones), a algunos interlocutores les resultó contradictorio e impensable, tratar al cuerpo muerto desde la perspectiva del embódiment, sobre todo porque este término está asociado fuertemente a los trabajos de Csordas y a la conexión con la reflexividad en el trabajo de campo. Las colegas de la mesa me impulsaron a pensar un concepto propio que, retomando las contribuciones de Csordas sobre el embodiment, me permita alejarme de las ideas asociadas a la reflexividad y focalizar sobre la agencia ${ }^{14}$. La metáfora corporeidad del muerto (aunque muchas veces corporeidad se utilice como traducción de embodiment) tal vez permita entender más claramente lo que intento iluminar acerca de la agencia del cuerpo muerto en el contexto social. Desde mi perspectiva, entonces, la corporización de la muerte se da a través del tipo de presencia del cuerpo y su estado/ubicación espacial, en tanto sujeto social en el que se encarna una historia social y relaciones sociales determinadas. Entiendo entonces que, lo que corporiza al cadáver, es "su lugar en el mundo", en donde las experiencias atravesadas por el muerto, las prácticas sobre sus cuerpos y los significados culturales establecen relaciones sociales determinadas entre los vivos (disputas e identidades encontradas entre ex combatientes y familiares, por ejemplo) y entre vivos y muertos.

Habíamos dicho que una de las manifestaciones que hicieron los familiares en la esfera pública en repudio por las demandas del CECIM fue la forma en que denominaban a los muertos en el Cementerio de Darwin como NN. Desde la perspectiva del antropólogo que lleva adelante la tarea de exhumación, podríamos decir que los muertos no son NN, pero los cuerpos sí, por lo que requieren de una identificación. Ahora, si uno entiende al cuerpo como un cuerpo-sujeto significante, desde una mirada que ubica "su lugar en el mundo", tiene que tratar de entender no solo que si el cuerpo es NN el muerto podría serlo también, sino también todo lo que la denominación NN puede implicar. Por ejemplo, la utilización de NN es común en Argentina para hacer referencia a los cuerpos de los desaparecidos de la última Dictadura Militar que fueron enterrados clandestinamente, por lo tanto, para los familiares de Malvinas no solo suele hacer 
referencia a lo que ha estado maltratado, oculto y abandonado, sino también a la victimización. Sin embargo, la Comisión de Familiares se ocupó durante muchos años de cuidar de los muertos en el cementerio. Se ocuparon de las cruces, de su mantenimiento, de rendirles honores a través de rituales específicos, de consagrarlos a partir del monumento, y de llevarles custodia a través de la Virgen de Lujan. En este sentido, no da lo mismo denominar al cuerpo de cualquier manera, ni tampoco su forma y locus de su ubicación espacial, porque retomando a Merlo-Ponty, el "Estar" en el mundo, del cuerpo muerto, hace referencia al muerto como sujeto histórico y social y en tanto tal a sus relaciones sociales. Es por eso que los familiares expresan en repetidas oportunidades que los caídos en Malvinas no son NN, que fueron con nombre y apellido, y que son héroes de la Patria.

Por otro lado, para los familiares que no pertenecen a la Comisión de Familiares y que no han compartido sus prácticas y representaciones para enfrentar la muerte, el pedido de las exhumaciones habilitaría el enfrentamiento a procesos obstaculizados. Así también, la forma de denominar al cuerpo en el cementerio como NN, afirmaría su necesidad de avanzar en lo relativo a cuestión Malvinas en función de un entendimiento del hecho en materia de Derechos Humanos:

Recién en el viaje que hicimos al cementerio nos enteramos que mi hermano no estaba identificado, fue terrible, eso alimentó la esperanza de mi familia de que estuviera vivo en algún lugar y mi abuela murió con la ilusión de que no hubiera muerto en la guerra, por eso quiero saber en qué lugar de ese cementerio está mi hermano. Imagino que de esa manera se va a saber también si murieron en combate, si murieron de hambre, si murieron porque los torturaron (Betty, 09-11-2016).
Entonces, solo una perspectiva que nos posibilite ver que en la muerte también el cuerpo humano es él mismo un sujeto, nos permite comprender, por un lado, la imposibilidad por parte de los familiares de disociar al cuerpo del hombre, y por el otro, la forma en que las denominaciones sobre los cuerpos que implican denominaciones sobre los héroes, podrían repercutir sobre las identidades y las relaciones construidas. Es así como, a través de los significados que le otorgan a los cuerpos y a la violencia ejercida sobre ellos, tanto familiares como ex combatientes, ya sea cual fuese su grupo de inscripción, se entienden como sujetos históricos, se identifican con la historia reciente, y se relacionan con los vivos y los muertos. Los cuerpos fueron entonces para la Comisión de Familiares, sacrificados, inhumados, bendecidos, fundidos en un territorio pretendido, protegido por la Virgen de Luján, visitados y honrados por los familiares. Por otro lado, desde la perspectiva de otros familiares y ex combatientes, los cuerpos fueron torturados, maltratados, abandonados, despojados de su identidad. Pero en estos usos, prácticas y denominaciones que se hicieron con/sobre los cuerpos/sujetos, estos/ellos se insertaron de una manera determinada dentro de la red de relaciones sociales.

\section{Exhumaciones e identidad ${ }^{15}$}

Avanzado el PPH, muchos familiares y ex combatientes que se negaban a las exhumaciones seguían hablando como en los primeros años de la posguerra en términos de 'profanación' o 'invasión'. Así lo manifestó un ex combatiente que integraba la audiencia en el seminario de la Cátedra Libre 'Malvinas Argentinas' de la 
Universidad Tecnológica Nacional de La Plata (en mayo del 2017) cuando preguntó al antropólogo del Equipo Argentino de Antropología Forense sobre las exhumaciones en términos de "invasión": "Aunque no todos los familiares quieran las identificaciones entiendo que las 123 tumbas deben ser invadidas igual desde un punto de vista de que es necesario sí o sí la identificación para el resto". Como vemos, los familiares de Malvinas enfrentaban el proceso de la exhumación en el marco de una serie de disputas que reflejaban las discusiones que venían dándose desde la época de la posguerra. En el marco de estas disputas, también circulaban rumores sobre el estado de las tumbas: "Tantos miedos que nos implantaron, que en el cementerio no había nada y que si abrían las tumbas era un sacrilegio y que si abrían las tumbas seguro los iban a trasladar" (Mariana, 13-12-2017).

Al tiempo que circulaban rumores sobre el estado de los cuerpos, se reprodujeron por diferentes medios de comunicación fotos que se infiltraron del trabajo que los antropólogos forenses estaban haciendo en el cementerio: "Los enfermos son los que piensan que a mi mamá le encanta ver los restos de su hijo después de 35 años" (Gabriela, 22/07/2017). Esta expresión es entendible porque la corporeidad del muerto estaba empezando a tener presencia de una manera que desafiaba el entendimiento que ellos habían tenido sobre la muerte en la guerra durante muchos años. Los familiares de la Comisión no estaban preparados para ese tipo de corporeidad, porque como ya había mencionado, el cuerpo del muerto yacía, fundido en la tierra, oculto y anónimo en muchos casos, pero cumpliendo un rol activo como guardianes de las Islas y de los vivos. En este sentido, debemos atender a las relaciones sagradas construidas entre los muertos y los vivos. Los altares domésticos, por ejemplo, que según lo planteado funcionaron a partir de la idea de sacrificio y del cuerpo fundido en la tierra, nos advierten que ciertas prácticas sobre los cuerpos podrían reestructurar las relaciones y prácticas establecidas.

Lo que las fotos de las exhumaciones venían a evidenciar era que lo que estaba ordenado, ahora estaba fuera de lugar. De repente, una muerte que había sido pensada en función de la ausencia del cuerpo (en lo que respecta a la identificación individual y a las prácticas asociadas a los rituales tradicionales) debía empezar a enfrentarse de otra manera. Mientras la corporeidad del cuerpo, proyectaba relaciones y representaciones en función de la protección de una geografía sagrada, pero lejana, ahora proponía nuevas formas de acercamiento al muerto y a la muerte.

Finalmente, el trabajo de los antropólogos y forenses liderado por el CICR logró el resultado positivo de 100 casos hasta el momento, de los 121 cuerpos exhumados. En el caso de la Comisión, fueron citados todos juntos y cada familia fue llamada de forma individual, para recibir los resultados en presencia del secretario de Derechos Humanos, integrantes del equipo que realizó las identificaciones, y escribanos, entre otros presentes. Lo que en un tiempo era percibido como una profanación o situación dolorosa innecesaria (Panizo, 2011) ahora era esperado con entusiasmo:

La Comisión de Familiares de Caídos en Malvinas e Islas del Atlántico Sur, recibirá el día miércoles 6 de diciembre en la secretaría de DDHH las notificaciones tan esperadas por nuestras Madres y familiares directos, la localización de las Tumbas en el Cementerio de Darwin. Quisimos estar juntos para darnos el abrazo que venimos compartiendo hace 35 años... 
Que Dios y la Virgen nos acompañe en este proceso y que cada familia se lleve lo que esperó durante más de tres décadas.

En las representaciones que los familiares se habían podido hacer sobre la muerte a partir de los testimonios de los sobrevivientes, varios visualizaban a los cuerpos descuartizados, diseminados en la tierra, o desaparecidos en el mar, entre otras representaciones, por lo que su identificación ni siquiera podía imaginarse: "Nos dijeron, que una bomba le cayó de pleno, y yo siempre le decía a ella... se fundió con la tierra... qué van a encontrar" (Isabel 13-12-2017).

Pero las identificaciones derribaron rumores, recuerdos e ideas preconcebidas, y sorprendieron enormemente a los familiares. Entre las sorpresas se destacan la de los familiares que tuvieron durante mucho tiempo la esperanza de encontrar a su familiar vivo, sobre todo en los casos en que los caídos fueron reconocidos como desaparecidos en el mar: "Era una época en que los militares no daban ninguna explicación. Entonces, más conjeturas porque uno decía: están prisioneros con los ingleses" (Ana, 26/02/2010). Haberse imaginado durante muchos años que el desaparecido en combate estaba vivo o que no podía ser identificado por encontrarse en el mar, sumado a los rumores acerca del estado de las tumbas, hizo en algunos casos que las identificaciones no se esperasen en lo absoluto:

La novedad que tuvimos la semana pasada fue una sorpresa increíble porque nosotros veníamos a buscar el negativo directamente. Daban tantas vueltas que pregunté, “¿dio positivo?” Me dice, "sí” "uh, ¿pero están seguros?" Obviamente que estaban seguros, pero bueno, fue la reacción de no poder ni si quiera entenderlo...y procesarlo (Raúl, 14/12/2017).
El padre de Raúl era un Marino mercante tripulante del Isla de los Estados que se había dado por 'desaparecido' junto con la mayoría de sus compañeros cuando una fragata inglesa derribó el buque. Pero su cuerpo había sido llevado por el mar a la costa, y fue encontrado sin identificación por la comitiva dirigida por el Coronel Cardozo, que se ocupó de llevar los cuerpos al cementerio de Darwin. La localización de este cuerpo, tan poco esperada, hizo que se activara la búsqueda para aquellos que habían pasado situaciones similares en el contexto de la Guerra: " $Y$ te imaginas cuando tiré la noticia en el grupo de chats de los familiares de los tripulantes, fue una bomba que estalló" (Raúl, 14/12/2017).

En la mayoría de los casos, la noticia de la localización de los cuerpos fue recibida como algo mágico, que dio felicidad y tranquilidad:

La verdad que lo que nos pasó a nosotros es mágico (Mariana 13-12-2017).

Y yo me agarré la cara y me puse a llorar no lo podía creer... alegría, todo fue alegría... y un alivio, bueno, como que se terminó la pesadilla (Mirta, 13-12-2017).

Lo tomamos con felicidad, a parte del dolor de la pérdida (Raúl, 14/12/2017).

En muchos casos también, la identificación vino de la mano con pertenencias del caído. Así a la familia Araujo le dieron entrega de una medalla, restos de la chapa identificatoria, y el carné del colegio, con la matrícula paga. La presencia del muerto se recibió por parte de la familia como una triple sorpresa: la de haber sido identificado, la de encontrarse objetos de su pertenencia, y la de enterarse de que el cuerpo se encontraba 'entero' a pesar de que los familiares creyeron durante mucho tiempo que le había caído una bomba encima: 
Tuvimos tres sorpresas, la primera que estaba, la segunda esta (muestra los objetos encontrados) y la tercera, que estaba entero". "Pero si le cayó una bomba", dije yo. Estaba muy lastimado en el pecho, tenía heridas mortales, nada más. Después entero. Tercera sorpresa, tercer alivio (María Fernanda, 13-12-2017).

Esta corporeidad, que derribo las representaciones del cuerpo "diseminado" se manifestó de diversas maneras, respecto no solo a la materialidad del cuerpo, sino a todo lo que hacía referencia a su historia en tanto sujeto. En este sentido empezaron a reconstruir la vida y la muerte:

La matrícula del colegio paga... Le digo a mi hermano “¿qué hacías con la matrícula paga? ja vos solo se te ocurre llevar esto!" porque mi hermano era así, entonces me doy vuelta y le digo a los chicos "este era el tío, que lleva la matrícula paga” empezamos todos a reírnos... Él era así, era la prolijidad, me dio mucha impresión porque era como que estaba mi hermano ahí (María Fernanda, 13-12-2017).

A mi viejo lo encontraron solamente con un par de medias... así que nosotros deducimos que estaría descansando en ese momento porque si estuviera trabajando en las maquinas estaría con un mameluco, así que nosotros calculamos que habrá terminado su guardia, habrá ido a ducharse y estaría descansando en el camarote, por eso solo le quedaron las medias puestas, pero...en las aguas frías no durás más de cuatro minutos, la hipotermia...y dentro de todo es una muerte placentera porque uno pierde el conocimiento de a poco y no sufre...Treinta y cinco años después vengo a darme cuenta que hay un capítulo más, un poco más de la historia de mi viejo... Sé dónde está, sé cuál es la tumba, sé todo (Raúl, 14/12/2017).

Así, el cuerpo entra en escena para hacer hablar de las acciones y personalidades de los cuerpos/sujetos y propuso un capítulo más en la historia de vida que estaba todavía en construcción. En esta historia de vida el tipo de muerte sin "sufrimiento" en el caso del padre de Raúl, o la recuperación del "cuerpo completo" como en el caso del hermano de María Fernanda puede contribuir a otro entendimiento de una muerte que se había imaginado dolorosa en el marco de una guerra.

La corporeidad del muerto que se manifiesta en el informe de los forenses, en las entrevistas y en las pertenencias recuperadas, trae recuerdos, estimula a determinadas acciones y pensamientos y repercute sobre las prácticas de los familiares. La muerte se empieza a habitar de otra manera y nuevos canales de comunicación empiezan a tener lugar:

Volvió... mi hijo hoy volvió a nacer. Yo agarré sus cosas, lloré y le hablé. Me puse contenta (María, 13-122017).

Y yo tenía ganas de salir corriendo, porque cuando yo caminaba con mi hermano, él me hacía correr. El tronco de él era más largo que el mío, y yo a veces le decía "vas muy rápido" porque yo tenía que apurar el paso, entonces se ve que en mi inconsciente automáticamente se fue a mis piernas y corrió, fue una sensación hermosa (Mariana, 13-12-2017).

Lo que se deriva de los testimonios y el trabajo de campo, es que las entrevistas en las cuales notificaron a los familiares sobre las localizaciones de los caídos fueron vividas como rituales mortuorios en donde la corporeidad del muerto, se hacía presente en un marco de reconocimiento legítimo y social sobre el acontecimiento. Estas prácticas, habilitaron la necesidad de querer estar con el muerto ya que durante tantos años no había sido posible:

Otra cosa también que me encantaría es que ahora en este instante haya un avión parado en la puerta de la Secretaría y salir del escalón y subirme al avión y que nos lleven (Mariana, 13-12-2017). 
Lo que tengo es ganas de ir, tocar, tengo ganas de acostarme a su lado (María, 13-12-2017).

Y ahora quiero ir hacia las islas (Raúl, 14/12/2017).

Querer estar cerca del cuerpo forma parte de este nuevo enfrentamiento a la muerte que propone para algunos la posibilidad de abordar de una manera distinta el duelo inconcluso: "cuando podamos ir a las Islas, yo creo que ahí vamos a terminar de cerrar el círculo y tener el duelo que venimos estirando treinta y cinco años" (Raúl, 14/12/2017).

El muerto tenía ahora una presencia corporal como cuerpo/sujeto localizado en un espacio simbólicamente denso para los familiares. Planificar el viaje para visitar al muerto/cuerpo localizado fue la tarea inmediata e irremplazable en ese calendario construido por y para los héroes. Había que ir lo antes posible a llevar las flores y volver a habitar la muerte, ahora corporizada.

\section{Palabras finales}

Habíamos dicho que los familiares de la Comisión de Familiares expresaron su rechazo a las exhumaciones de distinta manera a lo largo del tiempo. Lo que las narrativas de ellos iluminan acerca de la negativa es el modo en que en diferentes contextos sociales se enfrentaron a una posibilidad a la cual no estaban preparados para afrontar, ni convencidos de querer hacerlo, porque más allá del significado de los cuerpos como símbolos políticos, estos encarnan vivencias y relaciones sociales, por lo que las prácticas sobre los cuerpos podrían modificar dramáticamente las relaciones establecidas. Entonces, lo que hay detrás del cuerpo muerto como símbolo político en la arena pública, son las relaciones sagradas entre vivos y muertos en el ámbito privado. En este sentido, la corporeidad del muerto a través exhumaciones e identificaciones, generó sentimiento de felicidad, reencuentro y ambigüedad. Felicidad porque propuso un reencuentro con el muerto en un espacio social significativo, legitimado por el equipo forense encargado de las tareas de identificación. Dolor porque la presencia del muerto/cuerpo, a través de la identificación y las pertenencias encontradas, los enfrentaba a una muerte que no había sido procesada a partir de esta corporeidad: una corporeidad explícita, concreta, que no encajaba con el marco de interpretación previo del héroe nacional y colectivo. Esta corporeidad, que traía detalles de historias de vida y muerte, antes desconocidas, dio más protagonismo al cuerpo/sujeto, que ahora localizado contribuía a reconstruir nuevamente la muerte personal, focalizando en el quiebre de las relaciones sociales en el seno de la familia. Entonces, los cuerpos no entran en escena solo como símbolos políticos e ideológicos que reflejan las pretensiones políticas e ideológicas de los grupos, sino que también, entran en escena como cuerpos sujetos que encarnan relaciones sagradas entre vivos y muertos.

¿Qué pasará con los cuerpos identificados? ¿Serán reclamados por los familiares para ser traídos a La Argentina Continental? ¿Se desmantelará el cementerio y por lo tanto la soberanía simbólica sobre las Islas? ¿Qué ocurrirá con los altares domésticos? Estas y otras preguntas deben ser planteadas para futuras líneas de investigación. Pero sí puedo contribuir con dos conclusiones de acuerdo a los aportes retomados de la perspectiva de la antropología de la muerte y la corporeidad: 1) La muerte es un proceso que se atraviesa a partir del tipo de presencia que el muerto tiene 
en la vida cotidiana de los vivos y de acuerdo a las prácticas que se ejercen sobre su cuerpo. En el caso de los familiares de Malvinas, este proceso no se vivenció a través de periodos cortos de despedida y separación como ha sucedido con los muertos "comunes" en el seno de la familia, sino que fue experimentado a partir de diferentes prácticas originales y novedosas desde la posguerra hasta la actualidad. 2) Lo que resulta significativo de las prácticas sobre los cuerpos, es que no solo cobran importancia los diferentes sentidos dados a la muerte, la violencia, y la estancia del cuerpo, sino también la forma en que las diferentes prácticas corporales que intervienen sobre los cuerpos/sujetos, con o sin intencionalidad discursiva, dan cuenta de "su lugar en el mundo". Entonces, lo que las experiencias de los familiares y la literatura retomada nos revelan, es que el cuerpo muerto al igual que el cuerpo vivo, está en constante movimiento como materialidad no acabada.

\section{Notas}

\footnotetext{
${ }^{1}$ Se denomina comúnmente Guerra de Malvinas al conflicto bélico entre Gran Bretaña y Argentina que se dio en 1982.

${ }^{2}$ La ley que consagra a los caídos como héroes nacionales (Ley 24.950) o la que declara lugar histórico nacional al cementerio de guerra ubicado en Darwin (Ley 26.498), así como los certificados emitidos por el Estado que informaron sobre el fallecimiento del combatiente, entran dentro de las prácticas promovidas por el Estado que nos permiten hablar en palabras de Louis-Vincent Thomas de la "muerte socialmente reconocida" (Thomas, 1993:62).

${ }^{3}$ El cenotafio refiere a la tumba o monumento funerario que no posee el cuerpo del fallecido.

${ }^{4}$ El 28 de marzo de 1983, el gobierno dictatorial a través de la Ley 22769, declaró el 2 de abril, "Día de las Islas Malvinas, Georgias del Sur y Sandwich del Sur.

${ }^{5}$ Para profundizar en la idea de sacrificio en el Caso de la Guerra de Malvinas ver Panizo 2016b.

${ }^{6}$ De aquí en más las citas de los interlocutores tomadas de las entrevistas personales realizadas serán referidas con el nombre de pila y la fecha del día en que tuvo lugar el encuentro.

${ }^{7}$ Documento, "Las tumbas de los soldados argentinos desde la perspectiva británica". Comisión de Familiares de Caídos en Malvinas e Islas del Atlántico Sur, en Consultado en http://www. heroesdemalvinas.org.ar/ en mayo del 2012.

${ }^{8}$ Fragmento de un comunicado difundido por la Comisión de Familiares en diferentes medios... Consultado por última vez en https:// www.limiteinformativo.com/index.php/nacionales/7852-comunicado-
}

del-centro-de-veteranos-de-guerra-de-malvinas-de-apostoles, el $31 / 08 / 2017$

${ }^{9}$ Audio de un video filmado a Delmira de Cao, circulado por la Comisión de Familiares

10 "A los ponchazos" es una expresión del habla coloquial que significa que algo se hizo con dificultades, o de forma poco planificada y desordenada.

${ }^{11}$ Segmento extraído de una nota publicada por la periodista Agustina López en el diario La nación, en http://www.lanacion. com.ar/2034469-maria-f-araujo-lo-de-la-exhumacion-de-cuerposen-malvinas-se-hizo-a-los-ponchazos. Ultima vez consultado el 18709/2017

${ }^{12}$ Fragmento de un comunicado difundido por la Comisión de Familiares en diferentes medios. Consultado por última vez en https:// www.limiteinformativo.com/index.php/nacionales/7852-comunicadodel-centro-de-veteranos-de-guerra-de-malvinas-de-apostoles, el 31/08/2017

${ }^{13}$ Traducción propia del inglés.

${ }^{14}$ Se agradece en especial a Silvia Citro y Patricia Aschieri por sus aperturas y contribuciones.

${ }^{15} \mathrm{El}$ análisis sobre las exhumaciones y algunos temas aquí tratados son también expuestos en un artículo escrito en inglés denominado "Reconstructed deaths: to inhabit the death before and after the exhumations in the case of the Malvinas War" que está siendo evaluado para ser publicado en el Bulletin of Latin American Research. 


\section{Referencias bibliográficas}

Agamben, G. (2014). El uso de los cuerpos. Buenos Aires: Adriana Hidalgo editora.

Ansett, E. (2013). La larga vida de las fosas comunes: apuestas simbólicas y sociales del tratamiento de restos humanos del Gulag en la Rusia post-soviética. En Ansett, E., Dreyfus, J-M. \& Gariban, S. (Ed). Cadáveres impensables, cadáveres impensados, el tratamiento de los cuerpos en las violencias de masa y los genocidios, Buenos Aires: Miño y Dávila editores.

Citro, S. (2009). Cuerpos Significantes. Travesías de una etnografía dialéctica. Buenos Aires: Editorial Biblos.

Csordas, T. (1999). Embodiment and Cultural Phenomenology. En Gail Weiss and Honi Fern Haber (ed). Perspectives on Embodiment. New York: Routledge.

Eltringham, N. (2013). Exposición, ocultamiento y "cultura": la disposición de los cuerpos en el genocidio ruandés. En Ansett, E., Dreyfus, J-M. \& Gariban, S. (Ed). Cadáveres impensables, cadáveres impensados, el tratamiento de los cuerpos en las violencias de masa y los genocidios, Buenos Aires: Miño y Dávila editores.

Guillou, A. (2013). Temporalidad y definiciones de los cuerpos tras el genocidio jemer rojo. En Ansett, E., Dreyfus, J-M. \& Gariban, S. (Ed). Cadáveres impensables, cadáveres impensados, el tratamiento de los cuerpos en las violencias de masa y los genocidios, Buenos Aires: Miño y Dávila editores.

Ferrandiz, F. (2011). Autopsia social de un subtierro. En ISEGORÍA. Revista de Filosofía Moral y Política. 45, 525-544.

Hertz, R. (1990). La muerte. La mano derecha. México: Alianza Editorial Mexicana.
Jackson, M. (2010). Conocimiento del cuerpo. En Citro, S. (coord.). Cuerpos Plurales. Antropología de y desde los cuerpos. Buenos Aires: Editoral Biblos.

Merleau-Ponty, M. (1975). Fenomenología de la percepción. Barcelona: Ediciones Península.

Panizo, L. (2011). Donde están nuestros muertos: experiencias rituales de familiares de desaparecidos de la última dictadura militar en la Argentina y caídos en la Guerra de Malvinas. Tesis de Doctorado. Facultad de Filosofía y letras de la Universidad de Buenos Aires.

(2015). Los héroes santos: muerte y sacralización en el caso de los caídos en la guerra de Malvinas. Dossier: La guerra de Malvinas: experiencias, historia y memoria, Revista digital de la Escuela de Historia, 7(13).

(2016a). Among Bodies: Reflections on Ethnographic Work and the Repercussions of Exhumations and Identifications of the Disappeared of the Last Military Dictatorship in Argentina. Human Remains and Violence, 2(2),38.

(2016b). Cuerpos muertos, violencia y sacrificio: diferentes sentidos en el marco de la Guerra de Malvinas. Amerika [En línea], 15.

Thomas, L.-V. (1993). Antropología de la Muerte. Barcelona: Ediciones Paidós.

Turner, V. (2002). Dramas sociales y metáforas rituales. En Geist, I. (Comp.) Antropología del Ritual. México: Escuela Nacional de Antropología e Historia.

Verdery, K. (1999). The political lives of dead bodies: reburial and postcocialist change. United States of America: Columbia University Press. 